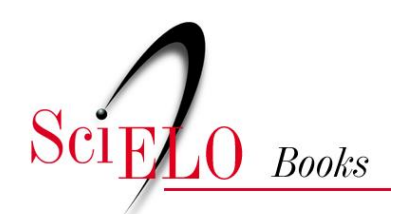

\title{
Viaje al centro de las TIC inclusivas
}

\author{
Rafael Sánchez Montoya
}

\section{SciELO Books / SciELO Livros / SciELO Libros}

SÁNCHEZ MONTOYA, R. Viaje al centro de las TIC inclusivas. In: GALLEGOS NAVAS, M., ed. La inclusión de las TIC en la educación de personas con discapacidad: relatos de experiencias [online]. Quito: Editorial Abya-Yala, 2019, pp. 29-45. ISBN: 978-9978-10-495-8. https://doi.org/10.7476/9789978104958.0003.

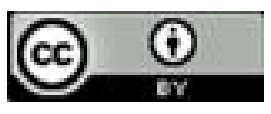

All the contents of this work, except where otherwise noted, is licensed under a Creative Commons Attribution 4.0 $\underline{\text { International license. }}$

Todo o conteúdo deste trabalho, exceto quando houver ressalva, é publicado sob a licença Creative Commons Atribição 4.0.

Todo el contenido de esta obra, excepto donde se indique lo contrario, está bajo licencia de la licencia $\underline{\text { Creative }}$ Commons Reconocimento 4.0. 


\section{Viaje al centro de las TIC inclusivas}

Rafael Sánchez Montoya

\section{Romper el estigma}

Eduardo tiene 7 años y sus padres no desean mandarlo a una escuela especial; quieren que vaya a una común. No camina, puede mover los brazos y mantener el tronco erguido y, si se le ayuda, da pequeños pasos. Sus padres le han comprado una computadora. Al principio no podía controlar el ratón pero ya puede hacerlo, siempre con mucha dificultad. Vive en una pequeña localidad y ha cursado preescolar. Tiene la suerte de que sus compañeros de clase colaboran con él y no es motivo de bromas. Su problema principal es que no articula ninguna palabra, así que no puede comunicarse oralmente. Los padres consiguen entenderlo gracias a un lenguaje de señas muy particular que se han inventado. Por favor, Eduardo necesitaría con urgencia un programa para que pueda comunicarse con la maestra.

La narración da luces para tratar el tema del uso de TIC por parte de los alumnos que tienen dificultad de comunicación, para aprender a vivir con autonomía o alcanzar las competencias establecidas en los currículos escolares.

Los docentes incluiríamos a Eduardo en el grupo de alumnos con Necesidades Educativas Especiales (NEE) o, como últimamente se hace con mayor precisión, alumnos con Necesidades Específicas de Apoyo Educativo (NEAE).

Si volvemos al correo observaremos a unos padres muy preocupados por el presente y, lógicamente, por el futuro de su hijo. Destaca- 
mos dos deseos que creemos que son paradigmáticos de la situación. En primer lugar, el querer que su hijo consiga un sistema de comunicación que le permita interactuar con los demás de forma legible, con autonomía y calidad. Y en segundo lugar, que realice su proceso de socialización y educación en un centro regular.

Conseguir estos deseos no es tarea fácil y supone luchar contra muchas barreras tanto físicas como mentales. La estigmatización es una de las más difíciles de superar, ya que supone ir contra viejas concepciones estereotipadas que conceptualizan actitudes negativas de la población con respecto a la NEAE. Se suele hablar de alumno discapacitado como un todo, y no de alumno normal que tiene una restricción o ausencia de capacidad para realizar determinadas actividades. Bajo el modelo del estigma es frecuente que algunas personas se refieran a los alumnos sordos como sordomudos, esto es un error pues pueden comunicarse de forma signada, oral o bilingüe. Otras veces se cree que las dificultades para comunicarse, por escrito o de forma oral, que presentan algunas personas con parálisis cerebral se deben a una discapacidad intelectual, cuando no es así e incluso muchas de ellas superan su déficit en el sistema nervioso central para desarrollar sus competencias lingüísticas utilizando un procesador de textos y la síntesis de voz, si su habla es ininteligible.

Recibir a alumnos con NEAE en un centro de educación regular es una de las experiencias más complejas y desafiantes para un docente, ya que supone adaptar la práctica educativa a las necesidades del alumno. El concepto de adaptación tiene un carácter amplio; para llevarla a cabo desearíamos contar con personal calificado que diseñe, si fuera necesario, un plan que permita:

- Modificar los espacios físicos y eliminar las barreras arquitectónicas hasta facilitar la movilidad en silla de ruedas o con bastón de ciego.

- Adaptar el equipamiento con un mobiliario apropiado a las necesidades de los alumnos desde el que resulte fácil acceder al equipo informático. 
- Acomodar el tiempo a los ritmos del alumno.

- Incluir ayudas pedagógicas (actividades complementarias para el aprendizaje del braille, Lenguaje de Señas, recursos TIC, etc.) y seleccionar una metodología que incluya, modifique o excluya los contenidos que se consideren convenientes.

No podemos olvidar que, aunque estamos a favor de la mayor inclusión del alumno. En ocasiones el "Aula abierta" especializada de educación especial ${ }^{3}$ en centros ordinarios es una opción cuando el alumno requiera de una atención individualizada, con adaptaciones significativas que no puedan ser atendidas en el marco del aula ordinaria con apoyos. El alumnado del "Ala abierta" compartirá con el resto de compañeros del centro espacios comunes y tiempos de recreos, así como actividades extraescolares, de acuerdo con las posibilidades planificadas para dichas acciones.

Partiendo de la opinión de Ken Robinson (2015) quien afirma que no sabemos cómo será el futuro para el que estamos educando pero que una de las pocas certezas es que el alumnado vivirá fuertemente condicionado por las TIC. Esta situación obliga a una reconceptualización de la educación especial, no es una tarea fácil pues sabemos que nuestro cerebro es experto en crear patrones de pensamientos rutinarios, casi mecánicos y por ello el advenimiento de las TIC habría que aprovecharlo para adquirir nuevas formas de pensar y actuar dentro del modelo de la Escuela Inclusiva.

3 En España las "Aulas abiertas" se encuentran ubicadas en un centro ordinario para aquellos alumnos que precisan adaptaciones curriculares muy significativas. Es destinatario de esta medida de atención a la diversidad, el alumnado con necesidades educativas graves y permanentes derivadas de: a) Discapacidad psíquica severa. b) Pluridiscapacidad: discapacidad sensorial auditiva y/o visual severa o profunda asociada a discapacidad psíquica; discapacidad motórica grave asociada a discapacidad psíquica, y discapacidad psíquica con alteraciones graves de comunicación. 


\section{2}

\section{Círculo de invisibilidad}

Una de las consecuencias de considerar a la discapacidad como un estigma es que muchas veces las personas son excluidas de las decisiones que les afectan como ciudadanos. Se acuerdan de aspectos muy importantes sobre sus vidas sin contar con ellos, como si fueran invisibles. Es como si estuvieran escondidas en el cuarto de atrás.

Sin duda es injusta la expresión "otra vez nos han dejado fuera" es un sentimiento común en muchos estudiantes con NEAE al ver que sus gobiernos invierten en tecnologías que no pueden utilizar. De todas formas debemos ser optimistas y esperar que, gracias a la toma de conciencia de las entidades y gobiernos implicados, se vayan adoptando medidas para evitar que se perpetúe, en esta era tecnológica, el ciclo de invisibilidad de la discapacidad.

¿Cómo invertir este proceso? Partiendo del diseño del prototipo hasta su fabricación que se hagan visibles las necesidades de las personas con NEAE, es decir, que se tengan en cuenta los principios del Diseño Universal. Aplicar estos principios supone abrir las TIC a todas las personas, sin importar sus aptitudes motoras, sensoriales o cognitivas, $y$ conseguir que el software, el hardware y los aspectos ergonómicos sean amigables y satisfactorios para todos los usuarios. La propuesta es no crear entornos o productos específicos para un usuario medio imaginario, sino fabricar productos desde el punto de vista ecológico en el que se tengan en cuenta las necesidades e intereses de todos los posibles usuarios. Se trata de enfatizar al individuo, facilitar su inclusión, buscar la igualdad y no clasificar a los productos e individuos por déficit.

Un buen ejemplo de Diseño Universal es el software El árbol mágico de las palabras. ${ }^{4}$ Elaborado por profesionales especializados en la atención a niños y jóvenes con ceguera o baja visión. Han hecho un importante esfuerzo por cumplir las normas del Diseño Universal con 
el fin de que pueda ser utilizado por personas videntes. Independientemente de la calidad del software que puede ser debatida, no hay duda que se sitúa dentro de los principios de igualdad de oportunidades de la Escuela Inclusiva para que pueda ser utilizado por todos los alumnos.

\section{Inteligencia ambiental}

Si profundizamos en el deseo de romper el paradigma del déficit y navegar en el barco del diseño para todos, podemos avanzar y tomar un concepto más amplio y complementario para llegar al puerto tecnológico emergente denominado "Inteligencia Ambiental".

Esta concepción implica diseñar las TIC de tal manera que tengan en cuenta la presencia de la persona y la situación en la que se encuentra, adaptándolas y respondiendo a sus necesidades, costumbres y emociones. Consiste en integrar la tecnología en el entorno para que las personas se beneficien de sus funciones sin percibir que la usan, haciendo que sus interacciones sean amigables, fáciles y beneficiosas para todos.

De la Inteligencia Ambiental destacamos tres características:

- Ubicuidad, que le permite acompañar al usuario allá donde esté (hogar, escuela, medio de transporte, hospital, en movimiento por la calle, etc.),

- Invisibilidad por la posibilidad de pasar desapercibida en el medio físico.

- Inteligencia por su capacidad para adaptarse a las preferencias de la persona así como una perspectiva humanista frente al extendido determinismo tecnológico. Estas investigaciones involucran a expertos de diversas áreas de conocimiento como psicología cognitiva, ergonomía, ingeniería de software, filología, inteligencia artificial y otras.

5 Disponible en: https://goo.gl/vRSmHG 
La Inteligencia Ambiental es una bonita utopía que poco a poco va teniendo más presencia en la sociedad aunque realmente, ¿qué beneficios le puede reportar al estudiante?; para explicarlo pensemos en Catalina, que es una joven sin comunicación oral, con parálisis cerebral, que utiliza la computadora prácticamente en todos los entornos cotidianos. Las TIC se han integrado a su silla de ruedas con la misma naturalidad que un bastón de ciego o un audífono a otras personas. Gracias a ella, Catalina ha mejorado su nivel de independencia. Esta situación, sin embargo, sabemos que no es frecuente. Conocemos muchos alumnos que, gracias a su tablet o celular tienen un buen nivel de comunicación e interacción con sus compañeros, maestros en el colegio, familiares y amigos de su entorno; pero ésta se interrumpe cuando sale de los ámbitos mencionados, porque su computadora no cumple todos los principios de la Inteligencia Ambiental, en este caso el de ubicuidad.

\section{Las TIC andamiaje del desarrollo personal}

Utilizamos la metáfora del andamiaje -scaffolding- para explicar el papel de las TIC como estructuras de apoyo para que los alumnos que tienen dificultades dentro del proceso de Inclusión y gracias a las tecnologías son capaces de progresar y mejorar en su comunicación, su aprendizaje, el ocio, el control ambiental o la transición al mundo laboral, entre otras.

El andamiaje es un enfoque sociocultural del constructivismo cognitivo y social que se asienta, entre otras, en la Zona de Desarrollo Próximo de Vygotsky (1978), en la neurociencia (plasticidad, inteligencia y estimulación) y en la Inteligencia Ambiental. Constituye una estructura que, de forma provisional o definitiva, aportan las TIC al alumno como un apoyo para su desarrollo personal. Hay estudiantes que requieren un andamiaje permanente, como los que tienen baja visión, ceguera, sordera, discapacidad intelectual, parálisis cerebral, trastornos del espectro autista, etc. y también otros, alrededor del 25\%, que sólo presentan dificultades temporales de aprendizaje: trastornos de 
atención, dificultades para el desarrollo de la lectura y escritura, dificultades para comunicar las ideas, etc. En estos últimos casos es posible retirar todos o algunos apoyos TIC una vez que el alumno alcanza el nivel requerido.

Las TIC ofrecen novedades y nuevas aplicaciones casi a diario ${ }^{6}$. Sus usos son múltiples y se distribuyen prácticamente en todos los campos de la actividad humana. Veamos algunas de las claves del contexto en el que se desenvuelven para conseguir tener éxito en los siguientes ámbitos: comunicación, educación, transición a la vida laboral, web social y ocio creativo, y control ambiental.

\section{Comunicación}

Alumnos como Eduardo, sin comunicación oral, ¿cómo pueden participar activamente en su clase o en su entorno? ¿Cómo demuestran sus conocimientos? ¿Cómo expresan sus sentimientos y opiniones? Sin duda la carencia de códigos, predominante en los procesos comunicativos como el lenguaje oral, es uno de los motivos principales de exclusión. Por ello es importante el papel del docente formado en TIC para que le ofrezca el andamiaje tecnológico y metodológico necesario.

Desgraciadamente, algunas personas -incluyendo a docentesequiparan la discapacidad para hablar con la incapacidad para pensar. Algunos suelen tener muy bajas expectativas para los chicos que no pueden hablar y le ofrecen muy pocas oportunidades para aprender. Entendemos las prisas de los padres de Eduardo para encontrar un medio de interacción con los demás. Si recordamos, en el e-mail que nos enviaron, nos decían que tiene un sistema de comunicación compartido con sus familiares que otros no pueden entender. Como señala Martha E. Snell (2006) esto es debido a que la comunicación no simbólica es idiosincrásica, es decir, surge por el conjunto de actos y significados que son propios y únicos

6 Recomendamos la consulta de https://goo.gl/36uKDr 


\section{6}

para cada niño. El sistema de comunicación es compartido por los interlocutores que ayudan a definir los significados e introducen y guían a las rutinas con un vocabulario predecible que se puede definir.

Las dificultades de comunicación producen muchas veces frustración y así algunos alumnos autistas o con discapacidad intelectual muestran su malestar con gritos, mordeduras, golpes y conductas de autolesión (Olmos, Cascales, y Alcañiz, 2017).

Para los alumnos con alteraciones en la comunicación y/o lenguaje los Sistemas de Comunicación Aumentativa y/o Alternativa pueden serles útiles como instrumentos para la terapia del lenguaje y el desarrollo del currículo. Su objetivo es proporcionar un conjunto estructurado de códigos no vocales que sirvan para llevar a cabo actos de comunicación (funcional, espontánea y generalizable). Las calificaremos de eficientes si los usuarios construyen competencias que les resulten útiles en su vida cotidiana y, a ser posible, que les ayuden a tener acceso a nuevos contextos lo menos restrictivos posibles.

Esta idea de funcionalidad de la comunicación ha llevado a dos profesoras (Figura 7), a poner en marcha un sistema de videoconferencia entre dos centros de Educación Especial con el fin de facilitar la comunicación y el desarrollo del lenguaje entre sus alumnos que utilizan tablero de Comunicación Aumentativa soportado por la computadora (Martínez, y Ribes, 2008).

Los alumnos que participan en la experiencia tienen una edad similar y no se conocen entre sí. Algunos tienen discapacidad intelectual y otras discapacidades múltiples. Comparten sus ganas de interaccionar con otras personas con intereses similares y la utilización de la Comunicación Aumentativa en sus centros. Utilizaron el programa OOVOO, ${ }^{7}$ similar al Skype pero con la ventaja de que su interfaz permite a los interlocutores verse con un tamaño mayor, lo que resulta de gran ayuda

7 Se puede bajar gratuitamente de: https://goo.gl/HCea9i 


\section{7}

para mantener la atención de los alumnos. También tiene la ventaja de que permite grabar la videoconferencia en la computadora para reproducirla posteriormente.

Figura 7

Formación de mensajes a través de pictogramas

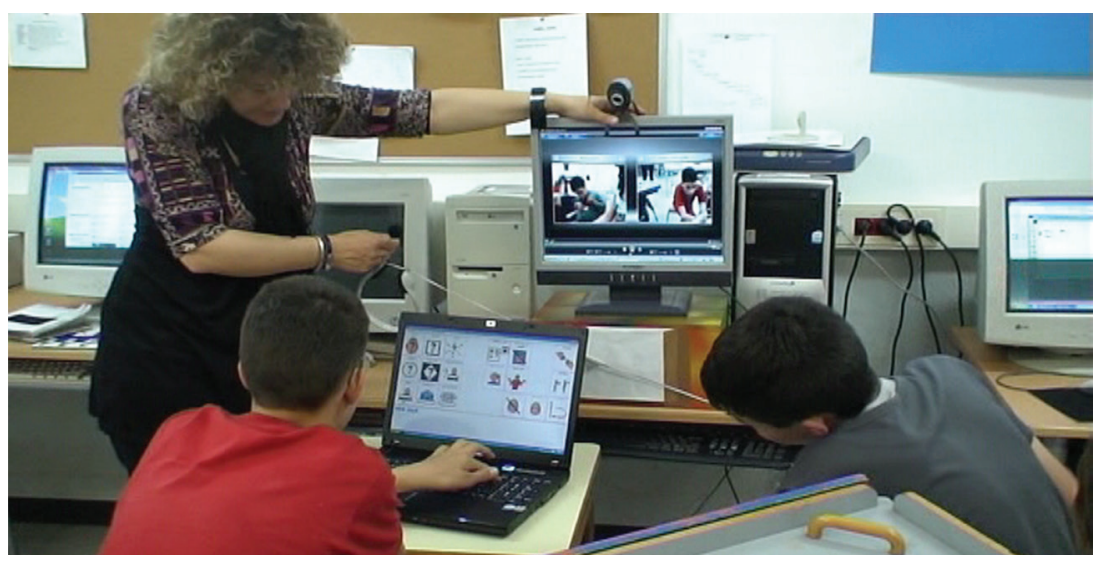

Los alumnos y su maestra seleccionan los pictogramas de la pantalla de la computadora para formar los mensajes en interacción con los alumnos de la otra escuela. La webcam registra sus imágenes. Foto: Rafael Sánchez (2017)

Las docentes se plantearon los siguientes objetivos: a) Reproducir situaciones comunicativas diversas. b) Exponer de forma ordenada hechos y vivencias. c) Iniciar e intervenir en una conversación sin salirse del tema. d) Respetar los turnos de palabra. e) Ampliar el vocabulario. f) Potenciar las diferentes funciones comunicativas. g) Utilizar, cuando fuera necesario, sistemas alternativos de comunicación basados en pictogramas del sistema SPC (Sistema Pictográfico para la Comunicación). ${ }^{8}$

8 Mayer-Jonson https://goo.gl/8JT53p 


\section{Educación}

El derecho fundamental de las personas con NEAE es la educación. Es instrumento primario y principal de inclusión pues de ella depende el pleno desarrollo de su personalidad y el aprendizaje de las competencias que le permitirán acceder, en el futuro, a un empleo adecuado, además de facilitarle o dificultarle su participación activa y responsable en la sociedad.

Muchos docentes encuentran en las TIC un medio ideal para facilitar interacciones positivas y aprendizajes entre los alumnos. La utilización de las TIC en el aula es similar a la de cualquier recurso, y para que sean eficaces es necesario conectarlas con el currículo escolar. Son muchas las investigaciones sobre sus efectos positivos. López-Escribano (2007) constata que la práctica de la lectura repetida con la computadora ayuda a los niños a desarrollar la fluidez, la ortografía y la comprensión lectora.

De forma general Marchesi et al. (2003) atribuyen a las TIC grandes ventajas en los aprendizajes de los alumnos:

- Capacidad para crear contextos de aprendizaje que abren nuevas posibilidades de información y de comunicación y conectan con algunas de las competencias que son necesarias para desenvolverse en el siglo XXI.

- Interactividad. Los estudiantes pueden adentrarse con más facilidad en experiencias de aprendizaje en las que reciben nueva información, están en contacto con otros aprendices, comprueban sus avances y dificultades y pueden ensayar estrategias diferentes para construir sus conocimientos.

- El software informático puede transformar nociones abstractas en modelos figurativos, lo que facilita su comprensión y su aprendizaje.

- La utilización de las TIC aproxima el entorno escolar a otros entornos del alumno (familia, amigos, etc.), lo que facilita la transferencia de los aprendizajes de unos contextos a otros.

- Las TIC pueden ampliar las relaciones de los alumnos y de los profesores con otros docentes y profesionales. 
Es frecuente leer informaciones que destacan que cada vez hay más tablets y computadoras en las escuelas y que se están haciendo importantes inversiones en capacitación pero, salvo experiencias aisladas, se publica poco acerca de los resultados que se obtienen de esas inversiones. Para obtener una información global sobre este hecho, vamos a tomar como referencia el estudio realizado recientemente por la Fundación Telefónica (2008) en más de 800 centros educativos españoles sobre el uso real de las TIC en primaria y secundaria.

El estudio de la Fundación Telefónica (2007) un panorama poco optimista ante las expectativas generadas por la introducción de las TIC como herramienta para innovar y transformar la educación. La opinión de los autores es que el profesorado, en general, se limita a utilizar las TIC en apoyo de las prácticas docentes tradicionales, de carácter transmisivo. Estaríamos lejos de la tipología de impregnación. Los profesores usan a menudo la computadora para preparar las clases, y los alumnos para realizar sus trabajos (tipologías suplementaria, complementaria y en menor medida integración), pero apenas se usan en las aulas de forma que impregne el currículo.

Los docentes tienden a utilizar las TIC de acuerdo con un cálculo racional coste/beneficio y acostumbran a incorporarlas en aquellas situaciones en las que no necesitan hacer grandes cambios en las prácticas preexistentes. Parece que si los gobiernos pretenden impulsar cambios importantes mediante las TIC, deberían replantearse previamente otros muchos factores, por ejemplo, que la mera presencia de los medios informáticos en los centros docentes no desencadena per se procesos de innovación docente.

\section{Transición a la vida laboral}

Los jóvenes con NEAE deberían tener el andamiaje necesario para realizar una transición eficaz de la escuela a la vida laboral adulta. Los centros docentes deberían ser activos y proporcionarles las destrezas 
necesarias para la vida diaria, ofreciéndoles formación en aquéllas que respondan a las demandas y expectativas sociales y comunicativas de la vida adulta (UNESCO, 2015). Los datos actuales revelan que muchas personas con discapacidades carecen de las cualificaciones adecuadas para el trabajo (Oficina Internacional del Trabajo 2008).

En relación a su incorporación al trabajo, casi la tercera parte de la población con discapacidad que accede al mercado de trabajo tiene como máximo dos años de estudios, una situación que necesitará cambiar para que puedan incluirse efectivamente en la sociedad y ocupar los puestos que tienen reservados por ley en las empresas.

CEPAL (2011) estima que en los países de América Latina y el Caribe es aún más seria la brecha doméstica (ciudadanos del mismo país) que la internacional. La falta de acceso a las TIC de la población con discapacidad genera un impacto devastador, incluso en aquellas personas que ya eran parte del sistema y que, por un accidente o por enfermedad, se ven obligadas a retirarse del mercado, en ocasiones de forma definitiva, aún en plena fase productiva de su vida.

Conseguir un empleo es el elemento clave para la independencia personal. El Empleo con Apoyo proporciona empleo dentro de empresas normalizadas a personas con discapacidad que tradicionalmente no han tenido posibilidad de acceso al mercado laboral, mediante la provisión de los apoyos necesarios dentro y fuera del lugar de trabajo, a lo largo de su vida laboral, y en condiciones de empleo lo más similares posibles en trabajo y sueldo a las de otro trabajador sin discapacidad en un puesto equiparable dentro de la misma empresa (Verdugo y Jordán de Urríes, 2001). En estos casos es destacable el papel del preparador laboral, el/la profesional de intervención directa que acompaña a la persona con discapacidad durante el primer periodo de su inserción en la empresa y desempeña su acción no sólo con el sujeto sino también con el entorno laboral.

El hecho de poder realizar parcial o íntegramente tareas de trabajo y estudios desde la vivienda o el trabajo puede facilitar la inserción en 
el mercado laboral de personas con ciertas discapacidades y darles acceso a estudios a los que no podrían haber asistido de otra manera. Para la realización de tareas de teletrabajo y estudios on-line de forma eficaz es fundamental disponer de una zona de trabajo diseñada adecuadamente y de las mejores aplicaciones informáticas posibles. Es necesario realizar una inversión mayor, y no solo económica, en este tipo de políticas activas, en lugar de continuar con la línea emprendida por algunos gobiernos basada en la pensión como máxima aspiración.

\section{Web social y ocio-creativo}

La facilidad con que se utilizan nuevas herramientas en Internet como los blogs, redes sociales, wikis o podcasts, está permitiendo que muchos usuarios, entre ellos los que tienen NEAE, tomen la iniciativa en la Red y no sólo con contenidos basados en sus necesidades e intereses sino también para establecer nuevas relaciones sociales que hasta ahora no parecían posibles. Este fenómeno lleva a la madre de Iago, niño de 9 años con trastornos del espectro autista, a relatarnos en su blog${ }^{9}$ algunos aspectos de la vida de su hijo y los logros que va consiguiendo. Con el apoyo de videos y de materiales de diferente índole, estos relatos son un punto de apoyo para muchas personas interesadas en compartir experiencias e informaciones sobre el autismo.

Los videojuegos también son una opción para el tiempo libre. Existe una opinión bastante generalizada de que no aportan nada bueno al desarrollo psicosocial de los alumnos, pero esto no siempre es así. Muchos de los juicios emitidos sobre el tema carecen de investigaciones rigurosas. ${ }^{10}$

9 Disponible en: https://goo.gl/JC19cw

10 A modo de ejemplo, la Revista Escuela de Salud, en el artículo "Videojuegos con riesgo" afirma: "Según los expertos, si se utilizan diaria y continuamente los videojuegos se facilita el niño la aparición de numerosos trastornos físicos y psicológicos, que pueden llegar a alterar su conducta y a transformarse en graves problemas psicopatológicos". 


\section{2}

\section{Figura 8}

Videojuegos que favorecen el movimiento ocular

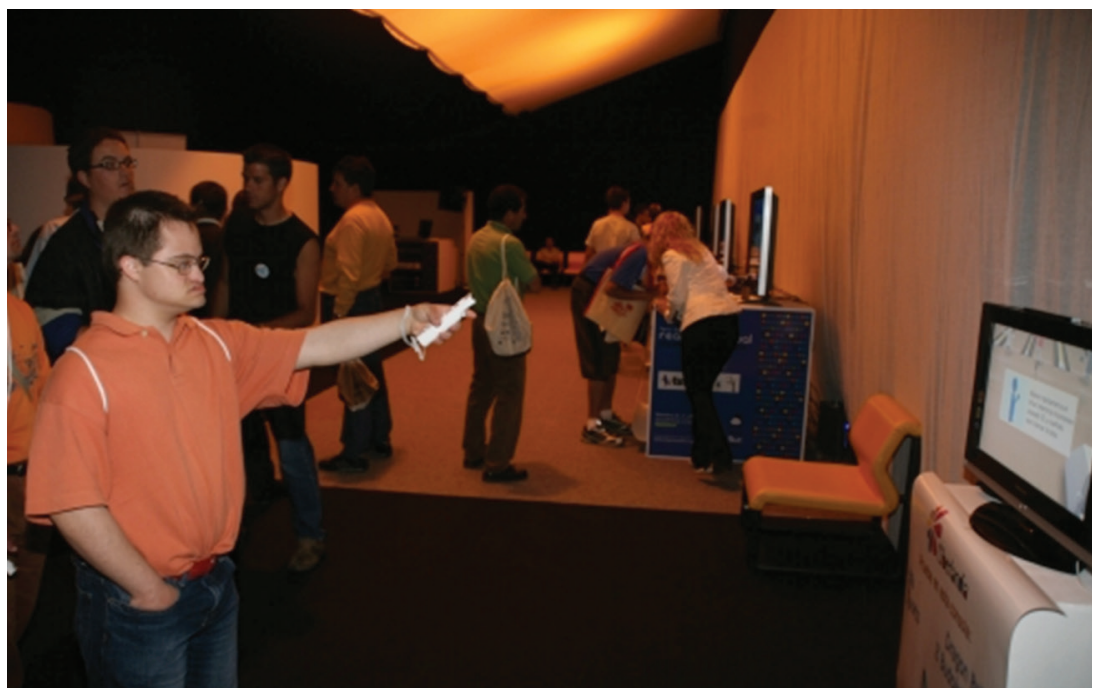

Con los videojuegos el usuario puede reforzar la capacidad de coordinación de sus movimientos oculares con los de pies y manos. Podemos estimular las diversas inteligencias e integrar las actividades del mundo virtual con sus propias habilidades al tener que adaptarse a las circunstancias y desarrollo del juego.

Foto: Fundación FREE. Feria Realidad Virtual, Ocio y Discapacidad. IMSERSO-España (2007)

En apoyo de los videojuegos surge McFarlane del Teachers Evaluating Educational Multimedia, ${ }^{11}$ quien ha investigado cómo se puede aprovechar la afición de muchos niños y jóvenes a este tipo de juegos para mejorar sus aprendizajes. En su trabajo Games in Education (2007), pasó diversos cuestionarios a 700 niños entre 7 y 16 años y obtuvo, entre otras, las siguientes conclusiones:

- Los videojuegos sencillos pueden ser una forma intuitiva de empezar a familiarizarse con la computadora o con un nuevo dispositivo que nos interese conocer.

11 Disponible en: https://goo.gl/1qdLWJ 
- Los videojuegos mejoran la comprensión lectora y las matemáticas.

- Los de simulación y aventura, en los que los jugadores deben crear sociedades y jugar en grupo, ayudan a desarrollar el pensamiento estratégico y de planificación y a relacionarse con otras personas. Se puede jugar en grupo al mismo juego, cada uno con un mando distinto, y además utilizar simultáneamente un chat de texto o de voz.

- A través de los juegos y simulaciones, adquieren un compromiso con el cumplimiento de una misión, la habilidad para desarrollar estrategias complicadas o la capacidad de hacer planes y adelantarse a los acontecimientos.

En la escuela de Yawata, el alumnado dedicó cinco minutos diarios a hacer ejercicios de inglés para mejorar su vocabulario durante un año y medio y sus notas subieron un 10\% de media. Como señalan varios autores su valor pedagógico es grande: resultan muy motivadores para la mayoría de los alumnos, lo que ayuda a crear situaciones de aprendizaje altamente significativas, y constituyen un recurso didáctico muy flexible dado que se pueden utilizar en una asignatura concreta, como taller o como eje transversal. Aportan múltiples posibilidades para el desarrollo de procedimientos tales como la adquisición de destrezas básicas, la autonomía, el razonamiento inductivo y deductivo, la creatividad, las habilidades y estrategias de resolución de problemas... y favorecen, además, el aprendizaje de contenidos que forman parte de las diferentes áreas curriculares (Gros, 2000; Gallego, 2000; Archambault 2000).

\section{Control ambiental}

¿Qué ventajas tiene para mí el uso del control de ambiental? se pregunta Gerardo Barroso, persona con discapacidad motriz en el congreso sobre Domótica, Robótica y Teleasistencia para todos celebrado en Madrid. Continuaba “...la lista sería enorme. Dentro de mi casa me cuesta mucho levantar una persiana, poner la calefacción, abrir determinadas puertas, las ventanas...". 
La idea del hogar digital cada vez la tenemos más cerca: alarmas técnicas para detección de humo, escapes de gas o agua; control de iluminación y persianas, comunicaciones de banda ancha en todas las estancias, servicios de entretenimiento, etc. y todo esto integrado y con posibilidad de control tanto desde el interior mediante pantallas táctiles, una computadora o un mando a distancia a través del televisor, o exteriormente desde cualquier punto mediante Internet o un teléfono móvil.

Los sistemas de domótica, robótica y teleasistencia presentan aún muchos interrogantes que dificultan su implantación generalizada. Uno de ellos es el precio que, aunque está cayendo, todavía es alto.

De forma más modesta, en las escuelas podemos poner en práctica los principios del control ambiental con la micro-robótica para desarrollar competencias de los alumnos con NEAE.

Así lo está haciendo el centro Ca'n Tangram con chicos con trastornos por déficit de atención con hiperactividad (TDAH). Sabemos que la TDAH se caracteriza por la impulsividad que conlleva a serias dificultades del alumno para controlar el procesamiento de la información, con corta latencia, alta tasa de respuesta y elevado número de errores. La presencia en las población infantojuvenil supone entre el 5-7\% a nivel mundial (Fenollar- Cortés, 2015; Montoya-Sánchez y HerreraGutiérrez, 2014) y los síntomas no remiten de forma espontánea y necesitan apoyos.

A partir de la adolescencia, los síntomas fundamentales disminuyen significativamente, sobre todo la actividad motriz, pero no desaparece. Es precisamente en esta edad donde los alumnos del colegio realizan actividades con micro-robots como Lego-MindStorm ${ }^{12}$ que utiliza un lenguaje muy visual e intuitivo que conecta con los intereses del alumnado y le permite desarrollar habilidades cognitivas deficitarias, con el propósito de potenciar las funciones ejecutivas e incrementar la 


\section{5}

autodirección de su comportamiento. Una de las técnicas más utilizada es la de Autoinstrucciones de Meichenbaum y Goodman que resumimos en el cuadro siguiente (Luque y Rodríguez, 2007):

Tabla 2

Resumen de fases

Objetivo: Enseñar a los alumnos con TDAH a hablarse a sí mismos cuando se enfrentan a la resolución de una tarea cognitiva: Comprender la situación, generar estrategias y controlar su comportamiento.

\begin{tabular}{|l|l|}
\hline \multicolumn{1}{|c|}{ Fases } & \multicolumn{1}{c|}{ Guía de pensamiento } \\
\hline - Definición del problema & ¿Qué es lo que tengo que hacer? \\
\hline - Aproximación al problema & ¿Cómo lo voy a hacer? \\
\hline - Focalización de la atención & $\begin{array}{l}\text { Tengo que estar muy atento y ver todas las res- } \\
\text { puestas posibles. ¿Estoy utilizando mi plan? }\end{array}$ \\
\hline - Selección de la respuesta & - ¡Ya está! Creo que la solución es ésta \\
\hline - Autorefuerzo & $\begin{array}{l}\text { ¿Cómo lo he hecho?: ¡Fantástico!, me ha sali- } \\
\text { do bien. } \\
\text { ¡Vaya!, me ha salido mal, ¿por qué?. ¡Ah!, jes por } \\
\text { eso!, la próxima vez me saldrá mejor. }\end{array}$ \\
\hline - Autoevaluación & $\begin{array}{l}\text { No he cometido errores, he seguido los pasos con } \\
\text { cuidado y despacio. } \\
\text { He cometido un error, debo ir con más cuidado y } \\
\text { hacerlo más despacio. }\end{array}$ \\
\hline
\end{tabular}

Fuente: Rafael Sánchez (2017) 